\title{
Los seres de la caña: un acercamiento a los Boneteros de la Ex Hacienda de Tuzamapan, Veracruz, México
}

The beings of the cane: An approach to the Boneteros of the former Estate of Tuzamapan Veracruz, Mexico

Héctor Adolfo Quintanar Pérez

Profesor de la Facultad de Antropología de la

Universidad Veracruzana

Fotoperiodista para Etnofotografía

https://www.facebook.com/Etnofotografia/

ORCID ID: https://orcid.org/0000-0002-

2687-7084

rangerquintanar@hotmail.com
Jesús Tenorio Simón

Fotógrafo independiente

https://www.facebook.com/pg/TenorioFoto-

grafia/about/?ref=page_internal

ORCID ID: https://orcid.org/0000-0003-

$3122-9628$

Recibido: 06-03-2017

Aceptado: 05-07-2017

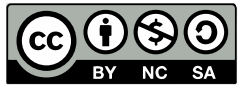

tenorioa77@gmail.com

\section{Resumen}

En este trabajo presentamos una mirada fotográfica de una expresión cultural de la localidad de Tuzamapan Veracruz, hogar de un personaje carnavalesco al que los lugareños llaman "Bonetero" por un elaborado sombrero adornado al que llaman bonete. Dicho personaje es caracterizado por los hombres adultos y viejos de la comunidad, quienes también portan una máscara de madera y visten un traje que asemeja al de la vieja imagen del hacendado local o al capataz del rancho, con sus botas de fuera, machete de madera y corbata elegante. Esta festividad muestra el pasado de esta comunidad, donde su clímax económico se debió a la aportación de la hacienda cañera de asentada en su territorio. Es en el mes de abril, cuando los habitantes salen a las calles y edificios abandonados de la ex hacienda y bailan con alegría durante más de cinco días de desfiles, haciendo gala de su ingenio con distintos disfraces, pero también rememorando sus orígenes a partir de la figura del bonetero, portando con orgullo su tradición.

Palabras clave: Tradición, fotografía, carnaval, México, Veracruz

\section{Abstract}

In this work we present a photographic look of cultural expression in Tuzampan, Veracruz - home of a carnival character that the locals call "Bonetero" for an elaborate adorned hat which they call bonnet. This character its personified by the adult and old men of the community, who as wear wooden masks and a suit that resembles the old image of the local landowner of the estate, with his boots not tucked in, wooden machete and elegant tie. This festivity shows the past of this community where its economic climax was due to the contribution of the sugar plantation settled in its territory. It is in the month of April when the inhabitants go to the streets and abandoned buildings of the once estate and dance with joy during more than days of parades, displaying their wit with different costumes, but also recalling their origins from the figure of the boneteros, proudly carrying this tradition.

Keywords: Tradition, Photography, Carnival, Mexico, Veracruz. 
J usto en el corazón de Veracruz, lugar estratégico por donde los conquistadores arribaron a inicios del siglo XVII para iniciar su proyecto de Virreinato en el continente americano, se encuentra un lugar que para propios y extraños se encuentra olvidado de la cotidianidad social y agenda política de las grandes urbes cercanas.

A primera vista se puede percibir una romántica percepción de nostalgia al vislumbrar unos grandes arcos por donde las personas pasan día con día rodeando lo que anteriormente fuera uno de los grandes ingenios cañeros de la región, una mega construcción carcomida por los años que se levanta airosa frente al embate del tiempo como esperando tener las viejas glorias que antaño sus paredes albergaron. Este lugar del que hablamos es el pueblo de Tuzamapan Veracruz, hogar de la ex-hacienda del mismo nombre, donde su propia historia se escribe entre fincas de café, caña y tradiciones carnavalescas, y donde sin duda su historia se remite a un personaje tradicional que sintetiza su historia: El Bonetero.

De tradición agrícola, el pueblo de Tuzamapan tuvo sus mejores glorias económicas entre los siglos XIX y $X X$, por ser uno de los bastiones de producción cañera de la región, surtiendo de productos derivados de la caña como el azúcar, panela y alcohol a la capital del estado y grandes ciudades vecinas, componiéndose su población en una diversa muestra de distintos procesos culturales que quizá den origen a su más grande y colorida tradición: el carnaval, donde el personaje del bonetero surge a relucir entre bailes populares y la alegría de propios y extraños.

En la imagen del bonetero podemos observar, como todos los procesos históricos por los que la población ha vivido y creado se ven reflejados en una imagen que nos puede ayudar al entendimiento de la identidad tuzamapeña. En sus elementos y atavíos, el personaje porta herramien- tas propias de las tareas hacenderas y ganaderas tales como espuelas, botas vaqueras y una larga moruna de madera que nos remite al pasado hacendado e incluso al presente, pues sigue siendo la corta de caña una de las principales actividades económicas de la región.

Uno de los elementos más llamativos resulta ser el bonete, un sombrero al que se adecuan adornos de papel en forma de flores y se destaca una máscara de madera con diseños hechos a memoria por los pocos artesanos que aún se dedican a la labor de trabajar a mano dicho elemento.

Durante el carnaval local, muy propio de una tradición africana, indígena y europea, que nos remite a la sincretización de costumbres, tradiciones y festividades de la cultura indígena local, europea y la población africana que llegó a esta región desde el siglo XVI a trabajar a esta zona, los boneteros danzan por las calles portando orgullosos el tocado e indumentaria con el cual se identifica la tradición de un pueblo, así como la herencia misma de los procesos históricos que conformaron Tuzamapan hasta lo que es hoy en día.

Desde sus orígenes hasta la actualidad, Tuzamapan basa su vida en la producción de la caña de azúcar, en anterioridad para las haciendas y hoy en día para ingenios azucareros locales, es por eso que llamamos al bonetero un "ser de la caña", puesto que en su existencia sintetiza los orígenes históricos de todo un pueblo y reafirma su identidad tradicional basada en la agricultura cañera. Por esta misma razón es importante preservar la tradición del bonetero, pues al perderse su significado dentro del contexto del carnaval, también se comienza a olvidar la propia historia de todo un pueblo.

(Texto: Héctor Adolfo Quintanar Pérez Fotografías: Héctor Adolfo Quintanar Pérez y Jesús Tenorio Simón) 


\section{Jesús Tenorio Simón}

Incursiona en la fotografía aun analógica en los Talleres Libres de la Universidad Veracruzana y se especializa en técnicas de arte audiovisual. Actualmente cuenta con más de 10 exposiciones fotográficas entre las que se destacan: tres participaciones en exposiciones colectivas de la Escuela Veracruzana de Cine, una de ellas en la Fototeca de Veracruz; "Vistas de Veracrúz" presentada en el Festival de las Artes de Poza Rica en su edición de 2015, y recientemente exhibida en el espacio de Fundación Silvina en la ciudad de Xalapa; exposición "Coatepec Pueblo Mágico" en la Casa de Cultura de Coatepec con motivo de la celebración del $9^{\circ}$ año como Pueblo Mágico (2015). Muestra fotográfica "Semana Santa en Ixhuacan" con el apoyo del Municipio de Ixhuacan de los Reyes, Ver. (2016); Exposición Fotográfica de Modelismo presentada en la $2^{\mathrm{a}}$ Exposición Nacional de Modelismo del Sureste llevada a cabo en el Museo Interactivo de Xalapa (MIX), presentada posteriormente en el Museo de la Caricatura de Veracruz; recientemente se presenta como parte del colectivo Cámara 4 en el Museo de la Ciudad de Veracruz con la exposición "La Luz de un Pueblo", una recopilación de imagen de fiestas patronales; entre otras así como siendo premiado en el concurso "Miradas de la Sierra Madre Oriental" en la categoría de Cultura y Tradición.

\section{Héctor Adolfo Quintanar Pérez}

Héctor Adolfo Quintanar Pérez (1990). Licenciado en Arqueología por la Universidad Veracruzana (2013). Maestro en Antropología por la Universidad Veracruzana (2016) México. Docente de la Universidad Popular Autónoma de Veracruz y docente en el Colegio de Bachilleres "Colegio las Hayas". Coodirector del proyecto arqueológico "Restauración del juego de pelota en la Zona arqueológica de Yohualichan" y Participación en proyectos arqueológicos como Panamá Viejo en la ciudad de Panamá (2012) y Proyecto arqueológico Refinería del Pacífico y rescate arqueológico "Ruta Viva" en Ecuador (2013). En la temporada otoñal del año 2017, también se involucró en un proyecto de rescate cultural de los antiguos oficios en la ciudad de Quito, Ecuador. Donde realizó un levantamiento fotográfico y documental de todos aquellos antiguos oficios que están a punto de desaparecer por la nueva dinámica comercial y modernidad de la vida cotidiana actual en el país andino Miembro fundador del colectivo "Etnofotografía" donde se registran tradiciones y expresiones culturales para su estudio antropológico y promoción cultural. 


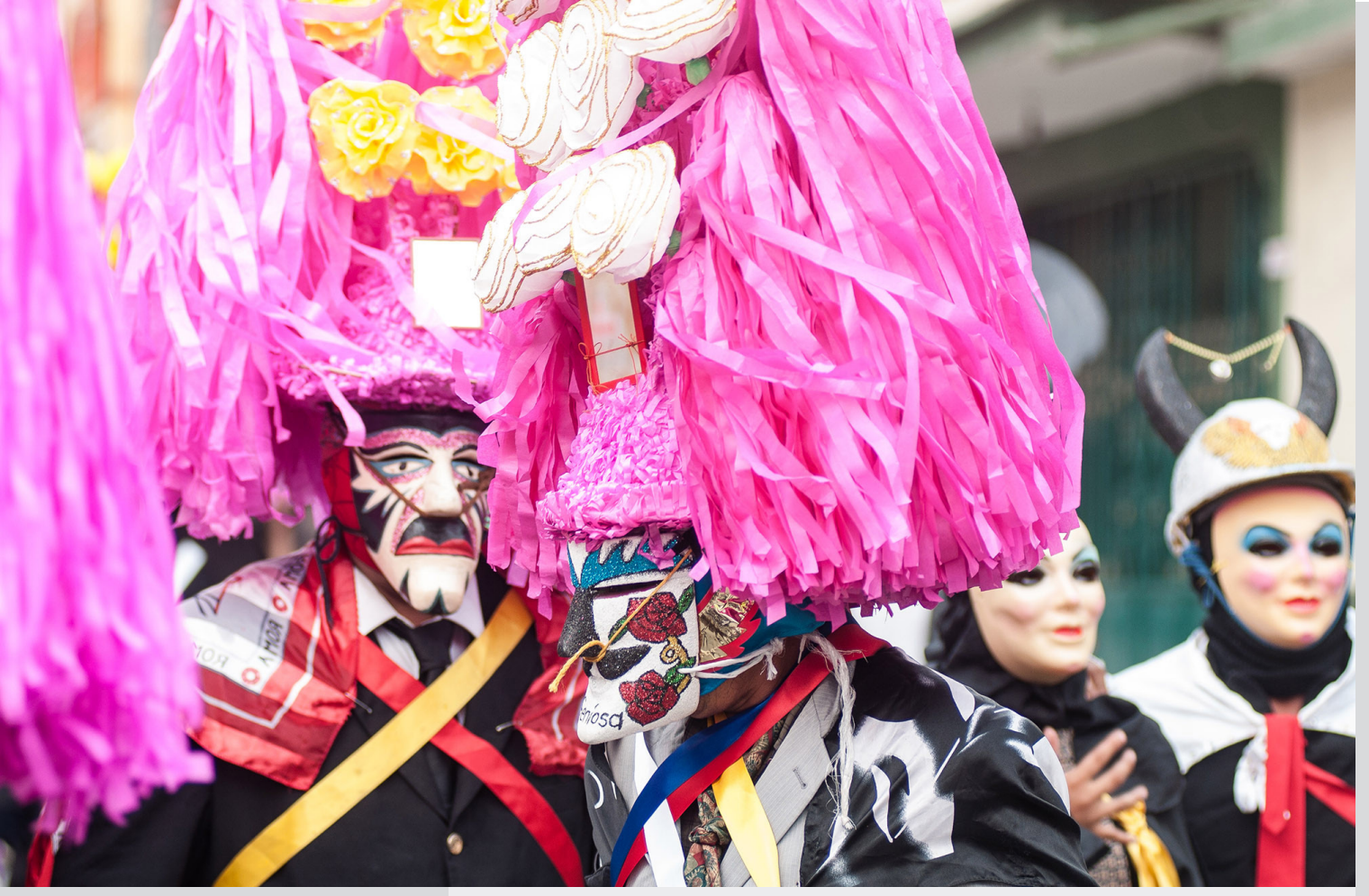

Bonetero en carnaval

(Foto: Héctor Adolfo Quintanar Pérez y Jesús Tenorio Simón)

Detalle de bonetero

(Foto: Héctor Adolfo Quintanar Pérez y Jesús Tenorio Simón)

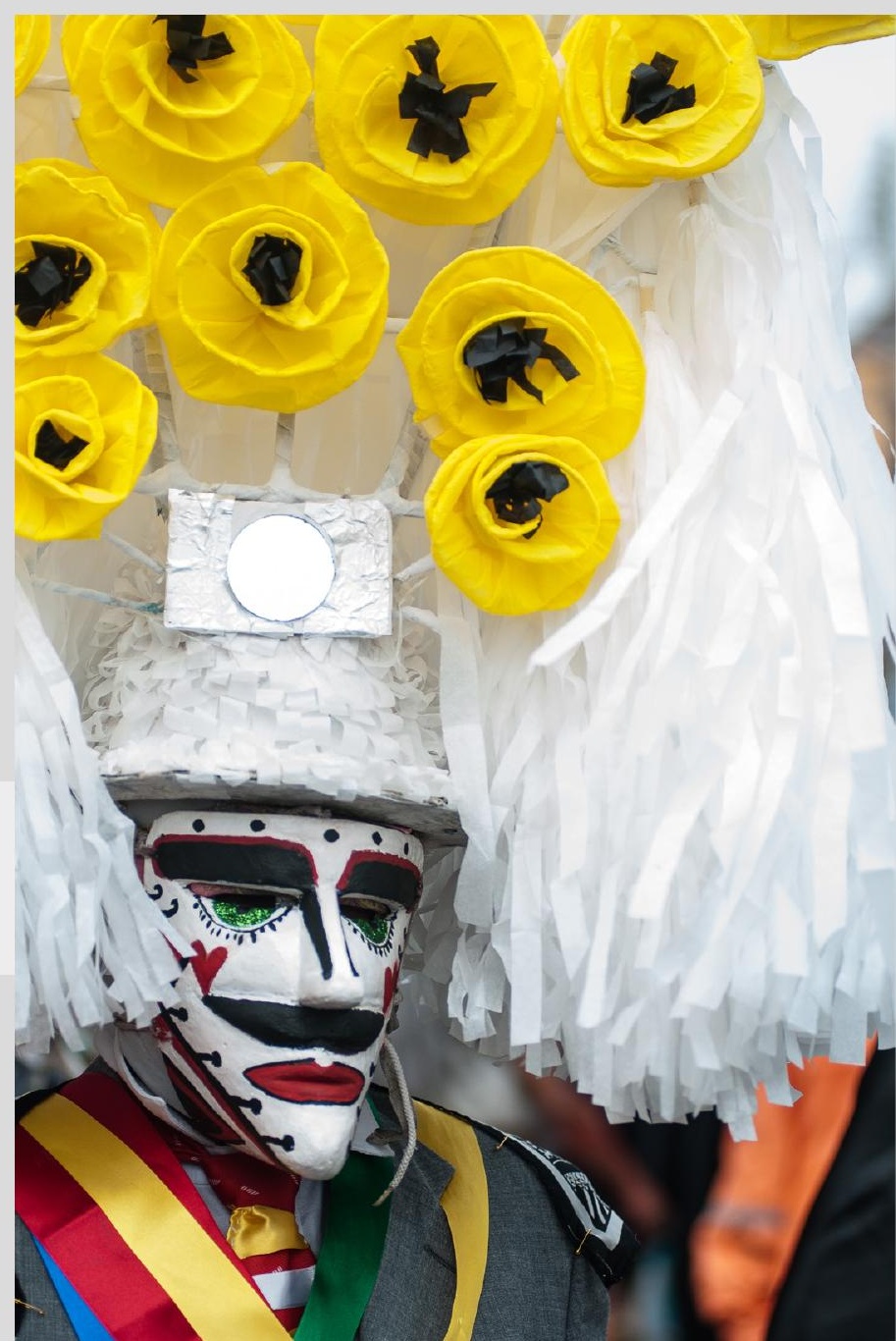




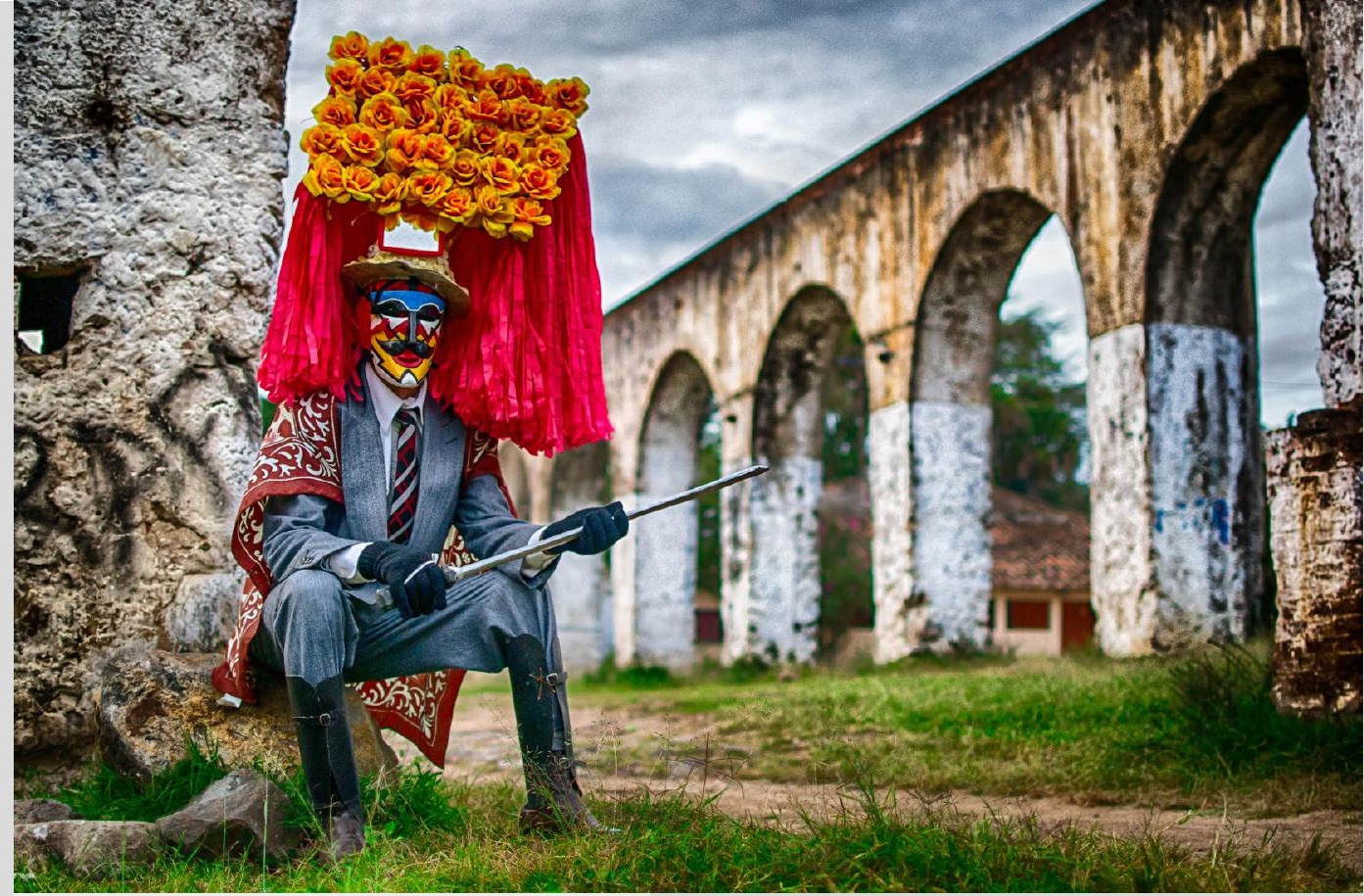

En las ruinas de la ex-hacienda

(Foto: Héctor Adolfo Quintanar Pérez y Jesús Tenorio Simón)

Detalle

(Foto: Héctor Adolfo Quintanar Pérez y Jesús Tenorio Simón)

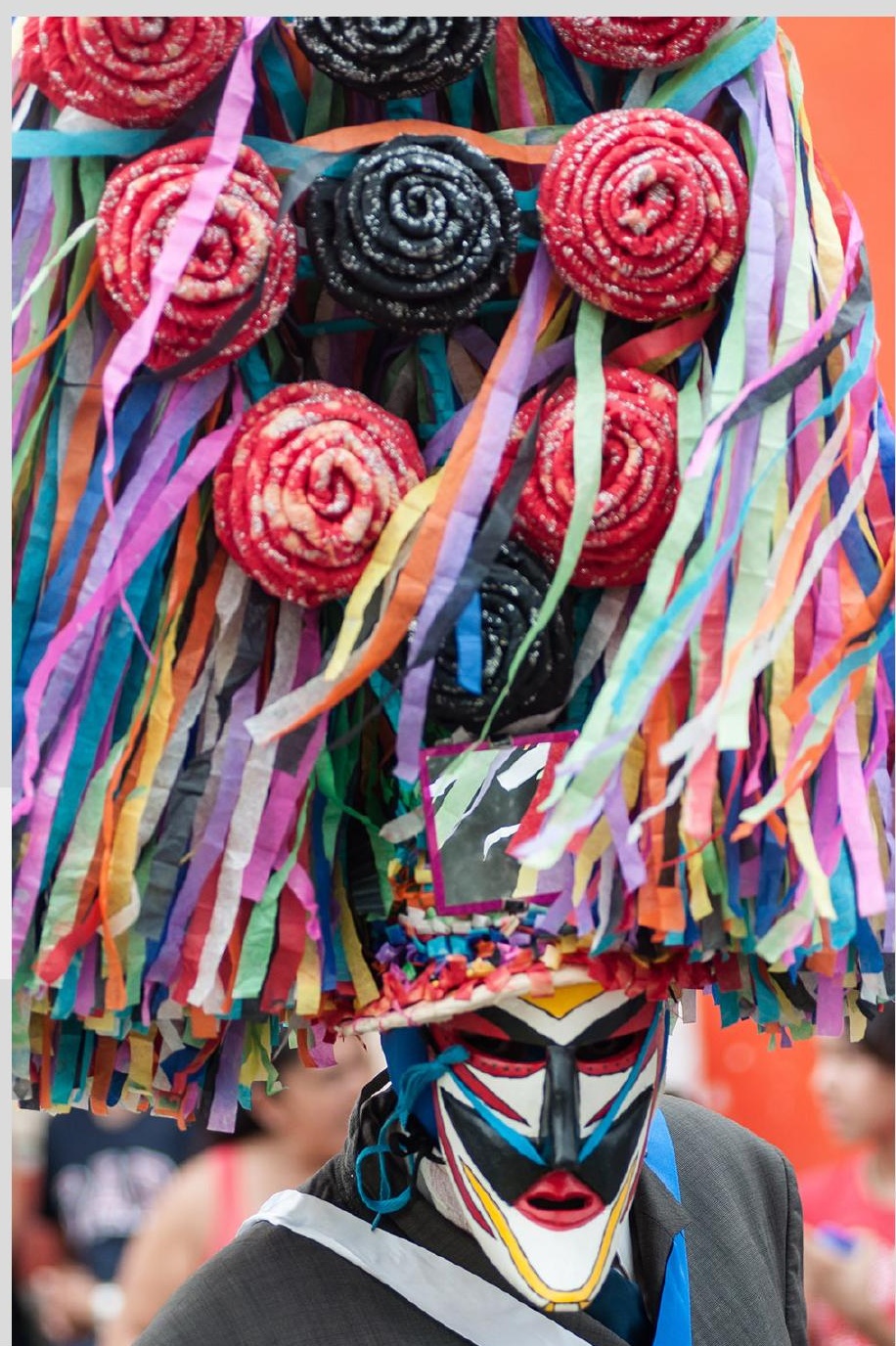




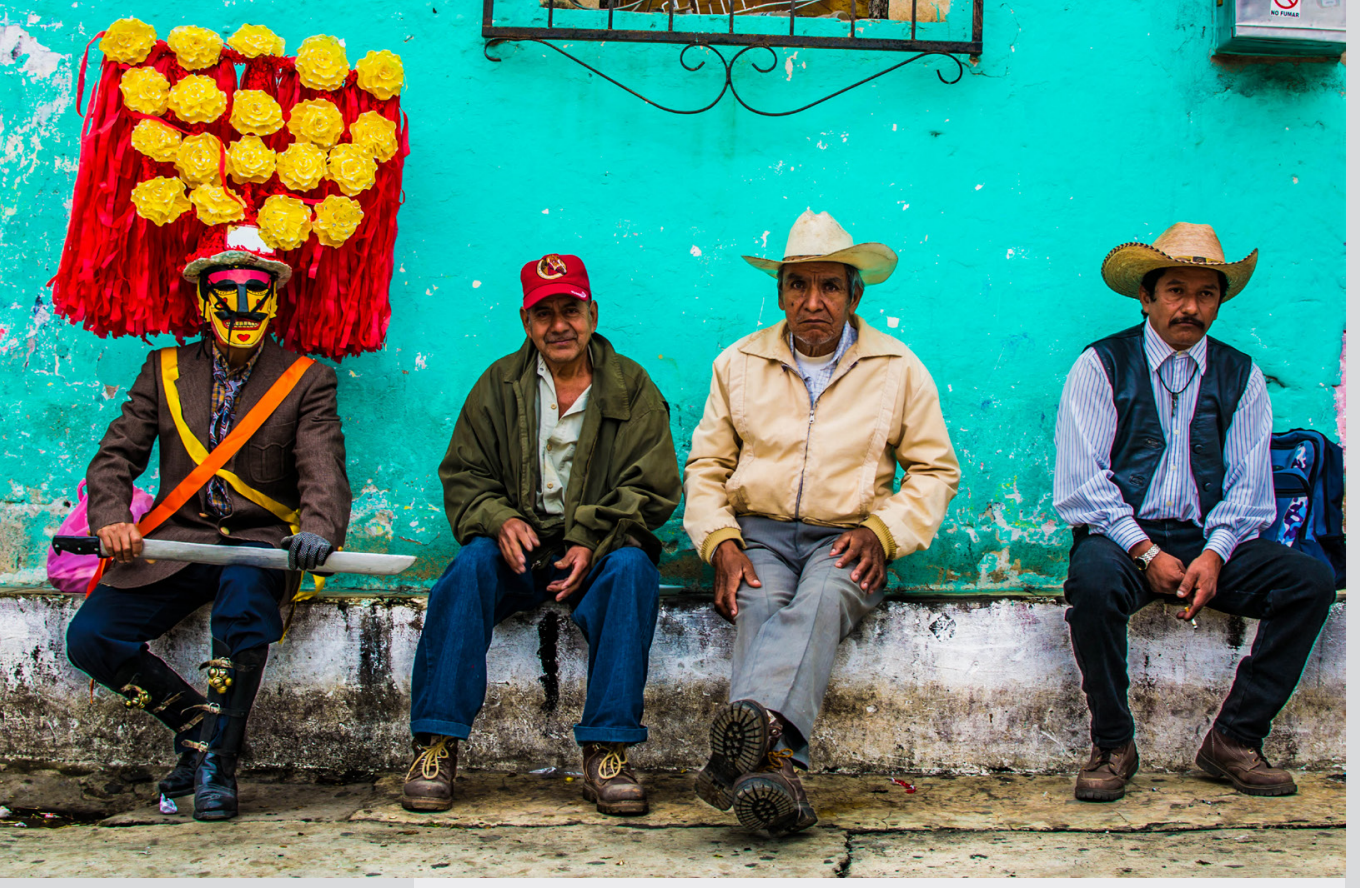

En la parada del bus

(Foto: Héctor Adolfo Quintanar Pérez y Jesús Tenorio Simón)

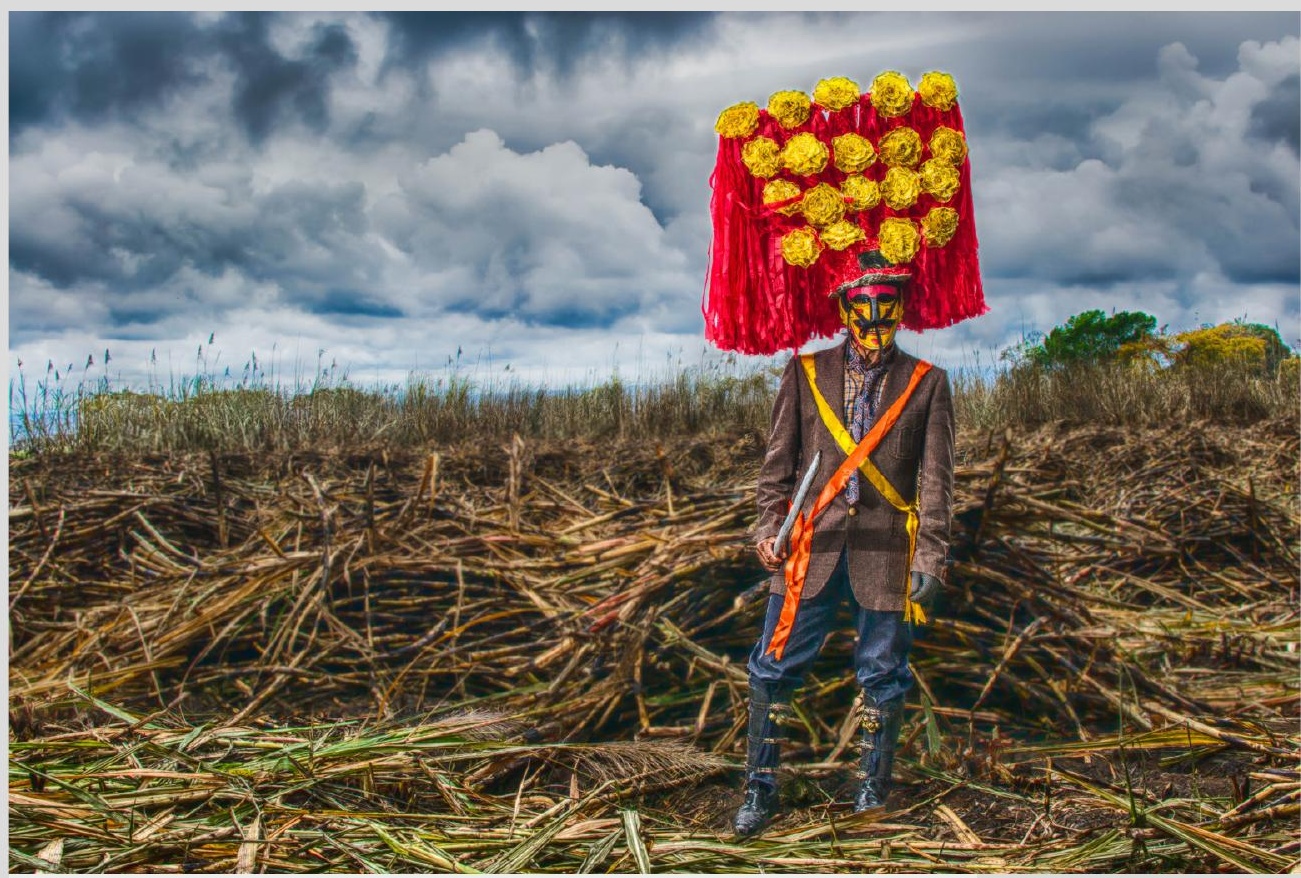

Entre cañales

(Foto: Héctor Adolfo Quintanar Pérez y Jesús Tenorio Simón) 